\title{
Research on Heavy-Rainfall-Induced and Hydraulic-Driven Geological Hazards in China (WCoE 2014-2017)
}

\author{
Yueping Yin, Yongqiang $\mathrm{Xu}$, and Wenpei Wang
}

\begin{abstract}
China Geological Survey (CGS) is one of the 15 new World Centres of Excellence (WCoE) in Landslide Disaster Reduction for the period 2014-2017. The title of the activities of the WCoE has been "Scientific research for mitigation, preparedness and risk assessment of landslides" since 2008, due to the complex conditions for the occurrence of geohazards in China. The Center of Geohazards Emergency of Ministry of Land Resources, which is directly under CGS, is responsible for the emergency response to major geohazards nationwide, including survey and investigation, monitoring and warning, risk assessment, prevention, training, and information systems. In this paper, the important activities of CGS are elaborated. The research project entitled "Research Project on the Early Recognition and Warning on Heavy Rainfall-Induced and Hydraulic-Driven Geological Hazards in China" was conducted from 2011 to 2015. From 2015 to 2017, a new project on mechanisms and hazards patterns of hydraulic-driven landslides has been conducted by the Center of Geohazards Emergency, China Geological Survey.
\end{abstract}

\author{
Keywords \\ Landslide $\cdot$ Heavy rainfall $•$ Hydraulic-driven
}

\section{Introduction}

Affected by global extreme climate change and ill-advised human activity, serious geological hazards induced by heavy rainfall still occur frequently in China. The catastrophic landslides that kill dozens of people and cause huge loss of property are still too difficult to recognize and mitigate. The research project entitled "Research Project on the Early Recognition and Warning on Heavy Rainfall-Induced Geological Hazards in China" was conducted from 2011 to 2015, co-funded by the Ministry of Sciences and

Y. Yin $(\bowtie) \cdot$ Y. Xu $\cdot$ W. Wang

Center of Geohazards Emergency, China Geological Survey,

Haidian, Beijing, 100081, China

e-mail: yyueping@mail.cigem.gov.cn

Y. Xu

e-mail: Xuyq@mail.cigem.gov.cn

W. Wang

e-mail: wangwp@mail.cigem.gov.cn
Technology, the PRC and the China Geological Survey, and hosted by Prof. Yin Yueping of the Center of Geohazards Emergency, China Geological Survey. From 2015 to 2017, a new project on the mechanisms and patterns of hydraulic-driven landslides is being conducting by Center of Geohazards Emergency, China Geological Survey. The research projects focus on three aspects: the forming mechanisms of rain-storm triggered landslides, early recognition and warning methodology and technology, and risk assessment, through the implementation of five sub-projects. The projects selected the Southeast China typhoon-rainstorm coast, the Wenchuan earthquake region, the Three Gorges reservoir, and other typical areas where catastrophic landslides frequently happened because of heavy rain and hydraulic factors to conduct the research. This includes the mechanisms of occurrence of geological hazards in heavy rain areas and the key methodology and technology of early recognition, emergency response, monitoring and early warning of geological hazards, and risk assessments based 
on the occurrence mechanisms of the geological disasters. Finally, codes and guidelines were formulated to improve the capacity and technological level of mitigation of rainfall-triggered geologic hazards.

Some research advances on typical landslides due to rainfall and hydraulic factors from 2011 to 2015 are briefly introduced below.

\section{Heavy-Rainfall-Induced Rockslide-Debris Flows After the Wenchuan Ms 8.0 Earthquake}

During July 7-12 of 2013, heavy rainfall occurred in the Wenchuan Ms 8.0 Earthquake area. The 5 days cumulative precipitation in the Dujiangyan area of Sichuan Province was up to $1129 \mathrm{~mm}$, which was rare in previous years and exceeded the mean annual precipitation of $1110 \mathrm{~mm}$ over the twenty-five years from 1987 to 2012 . The heavy rainfall triggered a rapid and long run-out rockslide in Sanxicun village. Its debris had a volume of 1.9 million $\mathrm{m}^{3}$, and it slid a distance of up to $1200 \mathrm{~m}$, killing 166 people in the village. The Sanxicun landslide was located in Zhongxing Town, Dujiangyan City of Sichuan Province. The site is located at (E10333'48”, N30'54'55”), $68 \mathrm{~km}$ from Chengdu City to the east, and $16 \mathrm{~km}$ from the Dujiangyan urban district (Fig. 1) (Yin et al. 2016a).
This area was famous for its agreeable climate and beautiful natural mountain scenery, lakes, and abundant vegetation. The typical natural conditions at resorts and vacation spots often concealed the potential for rockslides, rockfalls, and debris flows. This resulted in the misconception of a lower risk of geological hazards. This area enjoyed a high reputation stemming partly from the Qincheng Mountain-Dujianyan Scenic Resort and attracted many tourists every summer.

Therefore, research on rainfall-induced post-earthquake geologic hazards in these areas is significant for the reconstruction of towns and villages and tourism safety after the earthquake. The rockslide dynamic response characteristics triggered by the Wenchuan Ms 8.0 Earthquake and post-earthquake debris flow disaster have received much attention from researchers (Yin et al. 2009; Tang et al. 2011). Tang et al. reported a heavy-rainfall-induced debris flow disaster on September 24 of 2008 at the earthquake-ruined Beichuan town in the central part of the area affected by the Wenchuan Ms 8.0 Earthquake and presented the possibility that due to the ground shaking, the critical amount of accumulated precipitation and the hourly rainfall intensity necessary to initiate debris flows were reduced compared with values before the earthquake. Recently, Zhou and Tang (2013) summarized eleven rainfall events that induced debris flows between 2008 and 2012
Fig. 1 3D images showing catastrophic rockslide-debris flows at Sanxicun, in the Wenchuan earthquake region (red dashed line indicates the small rockfall due to Ms 8.0 earthquake)

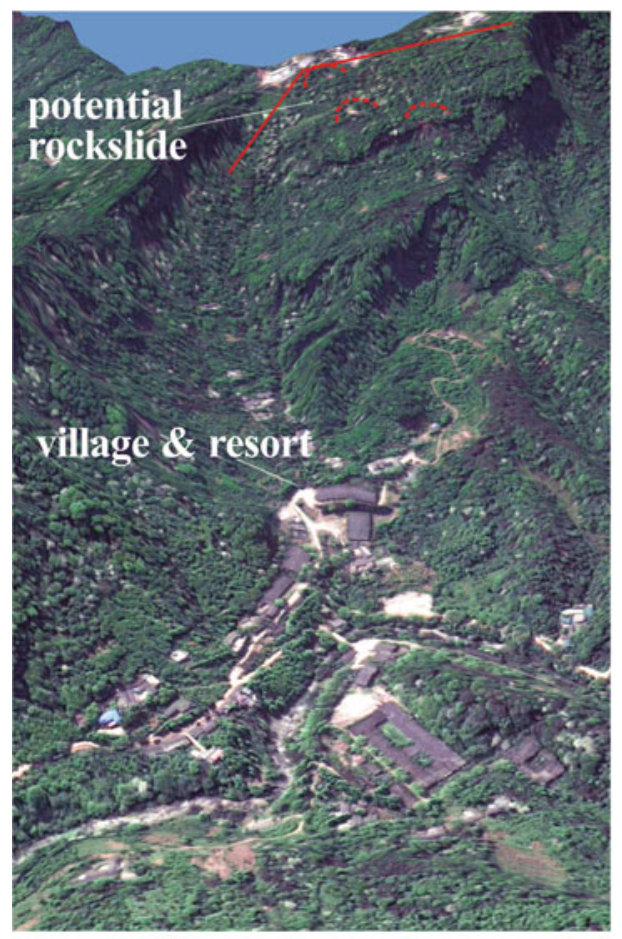

(a) Before sliding

Rockfall due to Ms8.0 earthquake

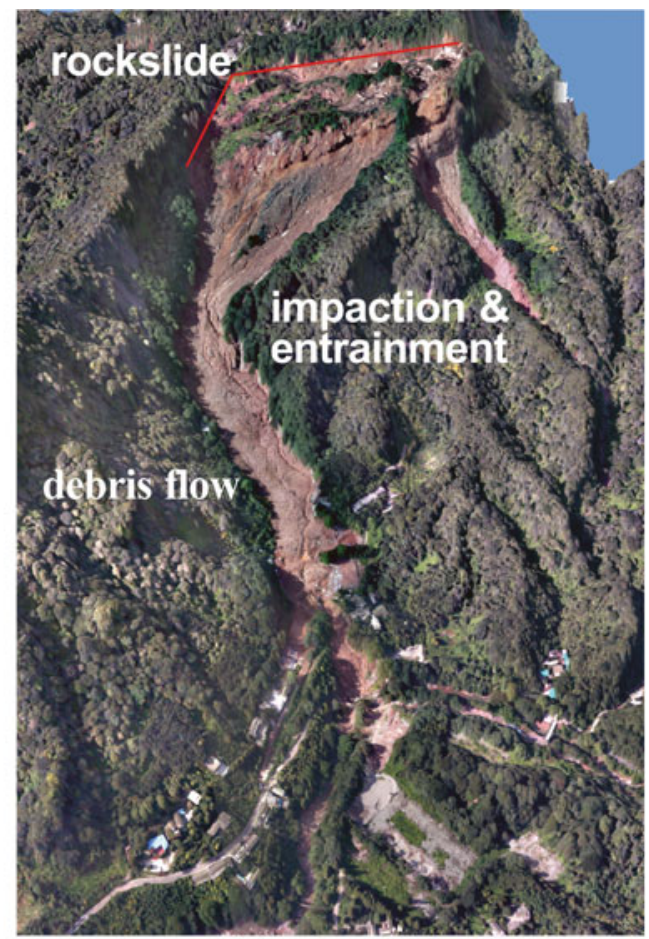

(b) After sliding Joint crack along sliding border 
after the Wenchuan earthquake, and discussed the rainfall thresholds for debris flow occurrence. However, research on rainfall-induced rockslides after the earthquake and their transformation into long run-out debris flows has made little significant progress.

The parent rock of the Sanxicun rockslide is a slightly inclined, nearly horizontal strata sandstone formation with intact rock constituents (Fig. 2). This rockslide was located southwest of the Wenchuan Ms 8.0 Earthquake fault and was only $12 \mathrm{~km}$ away from the epicentral region. The seismic intensity in the Sanxicun area was up to degree IX.

Based on the emergency investigation after the Wenchuan earthquake, three small-scale rockfalls were induced. Two rockfalls were at the margin of the slope of the rockslide source area and moved in the direction of $\mathrm{NNE} 10^{\circ}$, and the other was at the southeastern corner and moved in the direction of $\mathrm{NWW} 288^{\circ}$. The rockfalls disturbed or even damaged the slope. Research on this rockslide is significant for post-earthquake geological hazard prevention. Therefore, this project uses the Sanxicun landslide as an example to study the stability of fractured slopes after the Wenchuan Ms 8.0 Earthquake and the formation mechanism of rapid and long run-out rockslides triggered by heavy rainfall. The adverse conditions of the geological features prior to the rockslide are investigated, which provides a scientific basis for classifying hazard areas that should be subject to monitoring and prevention. The slope site was affected by the Wenchuan Ms 8.0 Earthquake in 2008. The sliding involved the thick fractured and layered rockmass with a gentle dip plane at Sanxicun. The formation processes included: (1) toppling due to shear failure at a high-level position,
(2) bulldozing of the accumulative layer below, (3) formation of a debris flow of the highly weathered bottom rockmass, and (4) flooding downward along the valley (Fig. 3).

After the shear failure of rock occurred at a high-level position, the rockslide moved for approximately $47 \mathrm{~s}$ downward along the valley with a maximum velocity of $35 \mathrm{~m} / \mathrm{s}$. This is typical for a rapid and long run-out rockslide. Finally, the research concludes that the identification of the potential geological hazards at the Wenchuan mountain area is crucial to prevent catastrophic rockslides triggered by heavy rainfall. The identified geological hazards should be properly considered in the town planning of the reconstruction works.

\section{Catastrophic Long-Runout Landslide in Zhenxiong, Yunnan}

On 11th January 2013 a catastrophic long-runout landslide (located at latitude 27 $33^{\prime} 5^{\prime \prime}$ and longitude 104 59'15') triggered by a prolonged low-intensity rainfall occurred in Zhenxiong, Zhaotong, Yunnan, southwestern China. This landslide destroyed the village of Zhaojiagou, killing 46 people, and burying over 60 houses in the distal part of its path (Fig. 4).

In the project, we selected the Zhenxiong landslide to examine the possible mechanisms and behaviour of this type of landslide from initiation to final deposition We conducted a series of ring shear tests on samples collected from the sliding surface and runout path to examine their shear behaviour under saturated conditions (Fig. 5). To determine

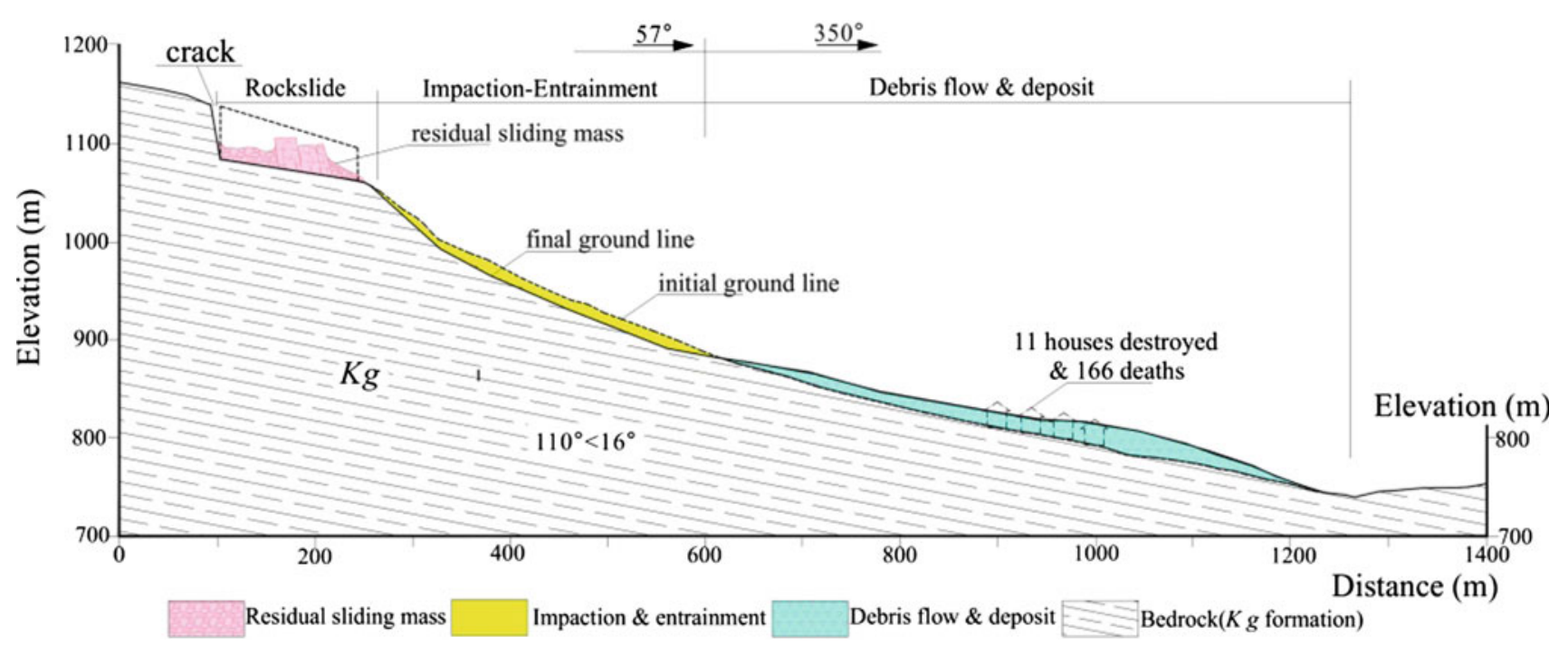

Fig. 2 Longitudinal profile of a rockslide-debris flow at Sanxicun, Wenchuan Ms 8.0 earthquake region 
Fig. 3 The debris flow, showing the height difference of about $15 \mathrm{~m}$ between the maximum level and the accumulation

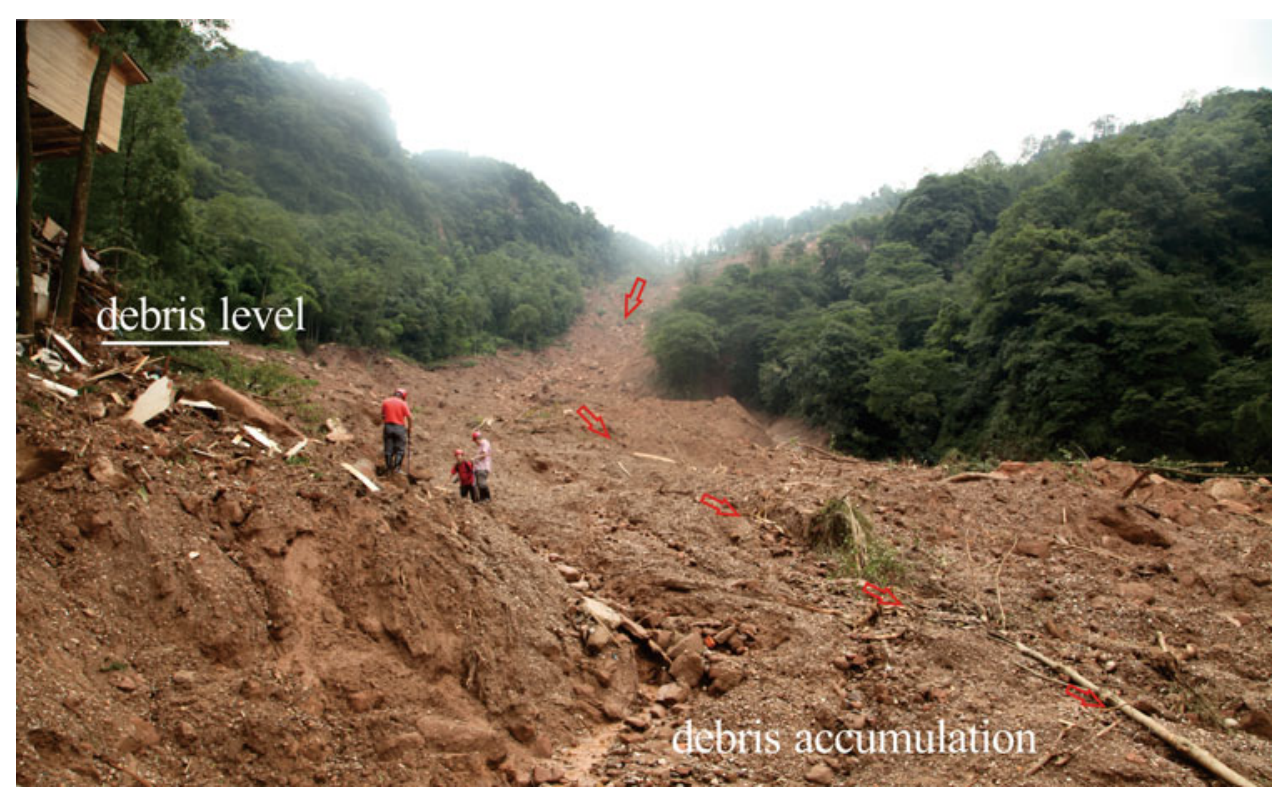

Fig. 4 Aerial view of the Zhenxiong landslide taken on 12 January 2013

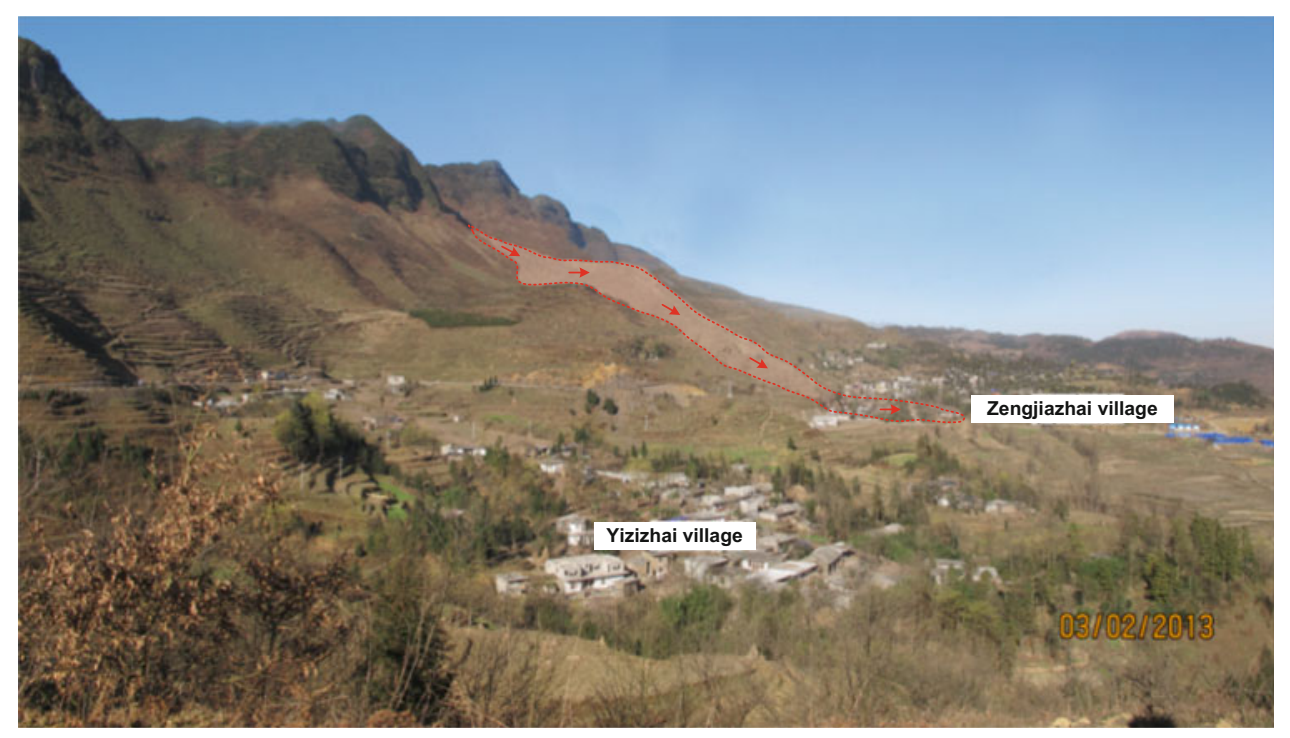

the appropriate rheological relationships and parameters to numerically model the landslide from initiation to final deposition, it is important to investigate the shear behaviour of source and runout path materials. Recently, a series of ring shear apparatus was developed and improved by the Disaster Prevention Research Institute (DPRI), Kyoto University (Sassa et al. 2010). These apparatuses enable shearing with different types of loadings under either drained or undrained conditions. We sampled the source (S1) and runout path material (S2) (Figs. 4 and 5e) and examined the shear behaviour of the samples using the ring shear apparatus (DPRI-5). Also, for hazard assessment of this type of landslide in the same area, it is essential to estimate its runout behavior, including travel distance and velocity. Based on the results of ring shear tests, we analyzed the post-failure behaviour of the landslide with the DAN-W model developed by Hungr (1995). It is expected that these models and parameters can improve the accuracy of hazard assessment for those areas with similar geo-environmental settings to the Zhenxiong landslide area.

The following conclusions can be drawn from this study (Yin et al. 2016b):

- The Zhenxiong landslide is a rapid and long-runout catastrophic landslide triggered by prolonged low-intensity rainfall. The undrained ring shear tests on the samples taken from the sliding surface and runout path reveal that the shear resistance of the samples can be decreased to a small value, and this enables the initiation and rapid movement of the landslide. 

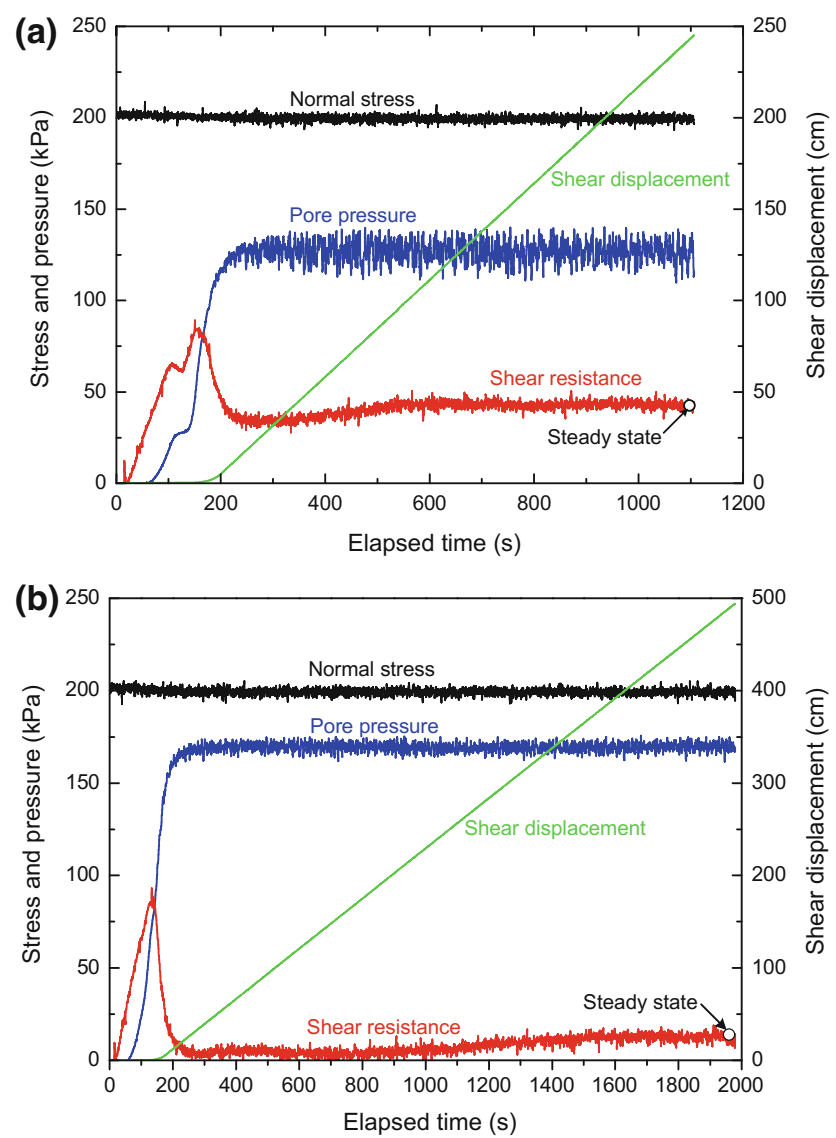

Fig. 5 Results of undrained ring-shear tests on the saturated samples taken from the source (a) and runout path (b)

- The partially drained test suggests that the shear strength of samples from the sliding surface is less affected by shear rate, while the shear rate has a negative effect on the shear strength of runout path material.

- The DAN-W model was used to simulate the post-failure behaviour based on ring shear test results. The results show that the mobilized friction angle obtained from ring shear tests provided the best performance in simulating this landslide. The total duration of the landslide is $48 \mathrm{~s}$ for an average velocity of $16.7 \mathrm{~m} / \mathrm{s}$. There is good agreement between the observed and simulated results, suggesting that this model, using parameters obtained through ring shear tests and back analyses, could be a useful tool for predicting post-failure behaviour in the same area, and the information used to mitigate this type of landslide hazard.

\section{Reservoir-Induced Landslides at Three Gorges Reservoir}

The Three Gorges region in China was basically a geohazard-prone area even prior to construction of the Three Gorges Reservoir. In September 2008, a trial impoundment of $175 \mathrm{~m}$ ASL commenced in the reservoir. The water level increased by about $100 \mathrm{~m}$ from the original water level of about $75 \mathrm{~m}$. In addition, a 30-m annual variation in water level was specified by reservoir regulations. As a result of the combined effect of the large water level variation, relocation, and other factors, the geological conditions in the Three Gorges area have been significantly changed, and challenges in terms of geological hazards prevention have been encountered in the Yangtze River (Yin et al. 2016c).

This project first presents the spatiotemporal distribution of landslides in six periods of $175 \mathrm{~m}$ ASL trial impoundments from 2008 to 2014. The results show that the number of landslides sharply decreased from 273 at the initial stage to less than ten at the second stage of impoundment.

Figure 6 shows the locations of landslides induced by six periods of $175 \mathrm{~m}$ asl trial impoundments. From a geographical perspective, reservoir-induced landslides are mainly distributed along the main streams and some branches of the Yangtze River. Because of the marked differences in geological environment conditions of slopes along the Yangtze River, major differences in landslide occurrences in various sections were observed.

Based on this, the reservoir-induced landslides in the Three Gorges region can be roughly classified into five failure patterns, i.e., accumulation landslides, dip-slope landslides, reversed bedding landslides, rockfalls, and karst breccia landslides. The accumulation landslides and dip-slope landslides account for more than 90\%. The Shuping accumulation landslides (a sliding mass volume of $20.7 \times 106 \mathrm{~m}^{3}$ ) in Zigui County and the Outang dip-slope landslide (a sliding mass volume of about $90 \times 106 \mathrm{~m}^{3}$ ) in Fengjie County are two typical cases; the mechanisms of reactivation of the two landslides were analyzed (Figs. 7 and 8). The monitoring data and factor of safety (FOS) calculations show that the accumulation landslide is dominated by water level variation in the reservoir, as most of the mass body is under $175 \mathrm{~m} \mathrm{ASL}$, and that the dip-slope landslide is controlled by the coupling effect of reservoir water level variation and precipitation, with an extensive recharge area of rainfall from the rear, and a front mass below $175 \mathrm{~m}$ ASL. 


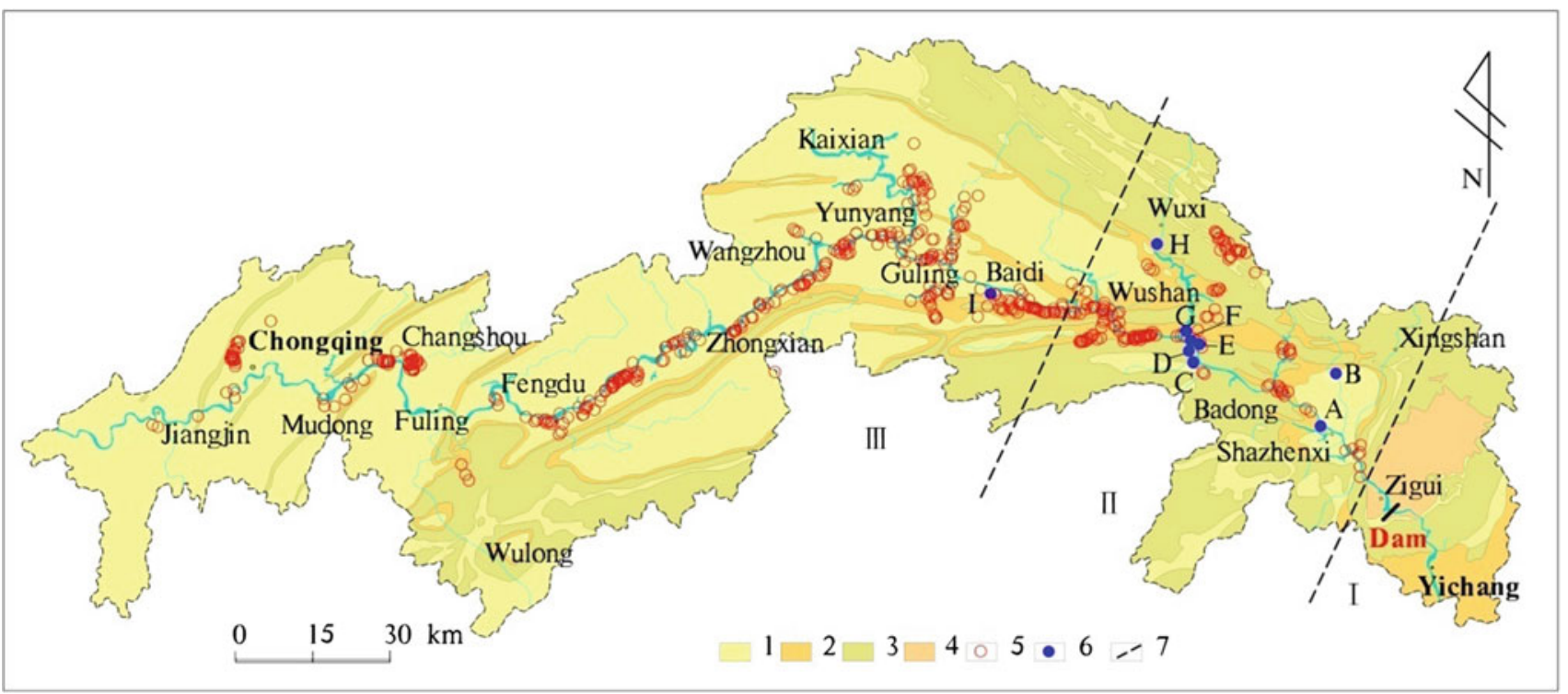

Fig. 6 Distribution map of landslides induced by six periods of $175 \mathrm{~m}$ asl trial impounding (Data from Sep. 1, 2008 to Aug. 31, 2014). Geology and locations: $\mathbf{1}$ sandstone, shale and coal strata, $\mathbf{2}$ mudstone mixed with sandstone and shale, $\mathbf{3}$ limestone, dolomite interbedded with shale, $\mathbf{4}$ granite, $\mathbf{5}$ six reservoir-induced landslides during $175 \mathrm{~m}$ asl trial impounding, 6 nine landslides described in the paper, 7 the section line of the reservoir region. Major landslides: A Shuping landslide, B Ni'erwang landslide, C Qingshi landslide, D Ganjingzi landslide, E Wangxia collapse, F Gongjiafang landslide, G Hongyanzi landslide, H Chuanzhu landslide, I Liangshuijing landslide
Fig. 7 Engineering geologic section for Shuping landslide in Zigui County, Hubei Province

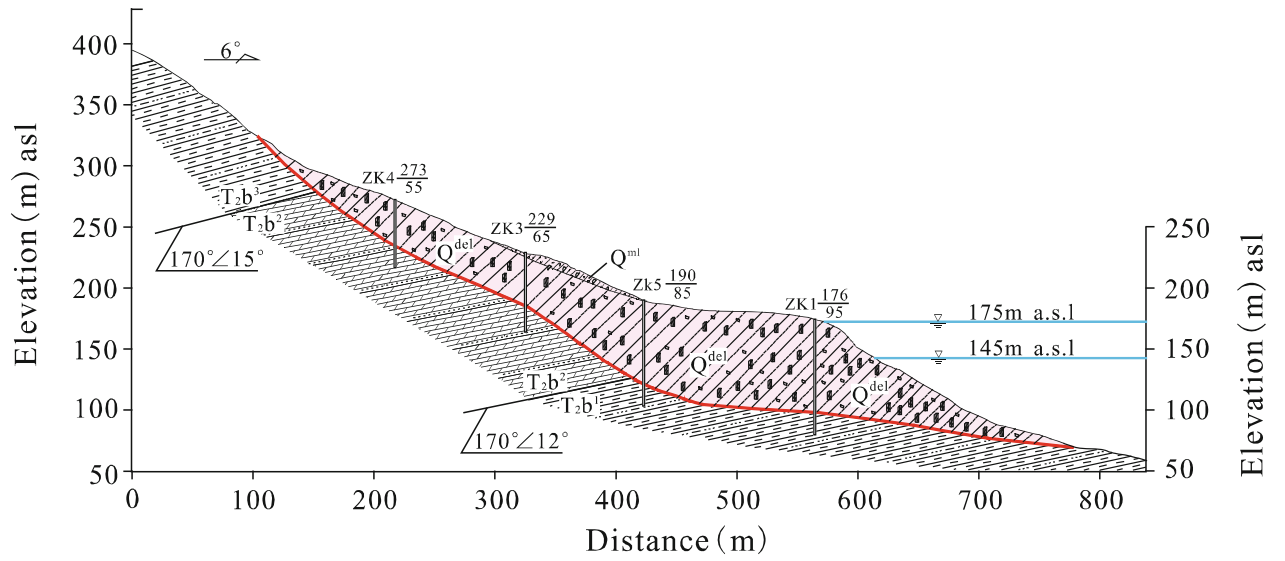

[ZK! $\frac{196}{95}$ Borehole $\frac{\text { Number }}{D e p t h(m)}$ Marlite\&shale

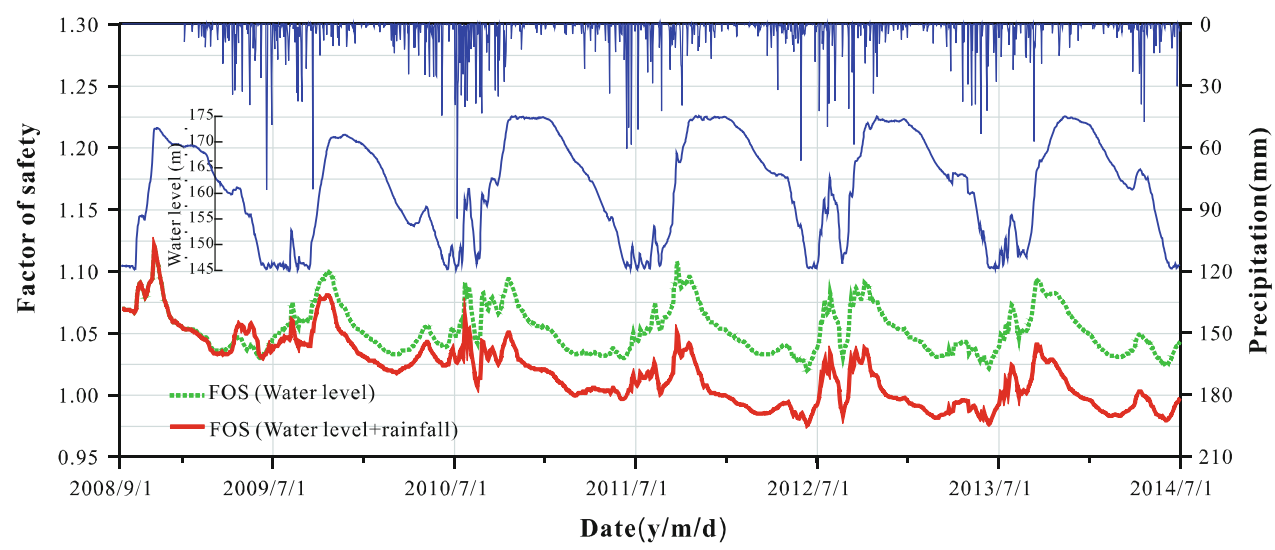

Fig. 8 Variations in the FOS of Shuping Landslide in Zigui County Hubei Province under the effects of water level and precipitation (data from Sep. 1, 2008 to Jul. 1, 2014) 
The characteristics of landslide-induced impulsive wave hazards after and before reservoir impoundment were studied, and the probability of occurrence of landslide-inducedimpulsive waves has increased in the reservoir region.

Simulation results of the Ganjingzi landslide in Wushan County indicate the strong relationship between landslide-induced surges and water variation, with high potential risk to shipping and residential areas. With regard to reservoir regulation in the Three Gorges, when using a single index, i.e., 1-d water level variation, water resources are not rationally utilized, and there has also been potential risks of disasters since 2008. In addition, various indices such as 1-d, 5-d, and 10-d water level variations are proposed for reservoir regulation. Finally, taking reservoir-induced landslides in June 2015 as an example, the feasibility of the optimizing indices of water level variations is verified.

\section{Catastrophic Landslide at the Shenzhen Landfill}

On December 20, 2015, a large landslide occurred at the Hong'ao Village construction solid waste (CSW) landfill in the Guangming New District of Shenzhen, Guangdong, China (103'33'48'E, 3054'55'N) (Fig. 9). The landslide involved 2.73 million $\mathrm{m}^{3}$ of construction waste, and had a length of about $1100 \mathrm{~m}$, making it the largest landfill slope failure in the world. Because the landslide killed 77 people and destroyed 33 houses within an industrial zone of Shenzhen, the State Council of China immediately organized an investigation team to look into the causes of the landslide. Prof. Yin Yueping (first author of this paper) was the head of the expert group within this investigation team. The CGS collectively produced the cause-analysis report for the State Council and conducted research on the failure mechanism of this landslide based on field investigations, unmanned aerial vehicle (UAV) drone 3D photogrammetry, the dynamic analysis of multiphase remote-sensing images, in situ and laboratory physical-mechanics tests, computer simulation, relevant archives, and witness interviews. With increasing volumes of waste and constant changes in a landfill's slope structures, the physical and mechanical properties and the hydrologic performance of a given landfill changes over time. Therefore, in contrast to analysis of natural landslides, the study of landfill slope failures must employ a dynamic analysis that probes into boundary conditions and stability. For this landslide investigation, we adopted a multistage modeling technique to study the influence of soil mass structure and hydrologic performance changes on the stability of the landfill landslide during different phases of placement. The dynamics of rapid long run-out sliding triggered by liquefaction after slope failure was simulated with LS-RAPID software. Finally, taking typical landfill landslides worldwide into consideration, this paper discusses controls on the geotechnical risks of urbanization (Yin et al. 2016d).

The analysis indicated that the Shenzhen landfill could be divided into a frontal unit (the landfill slope with low moisture content) and a rear unit (the placing unit with ponding and a high moisture content). This dual structure had two effects: first, surface-water infiltration, in that externally generated pressures at the back pond of fresh landfilled waste were higher than would be the case under normal hydrostatic conditions in an existing landfill slope; and second, consolidation seepage, in that the externally generated load from upper placement of waste in steps leads to excess pore pressure in the lower saturated soil body. Therefore, groundwater seeped from the rear unit into the front unit, causing a decrease of stability of the front slope, and inducing the landslide.

We applied a multistage modeling technique to study the various characteristics of CSW landfill's slope structure during the five stages of CSW placement, and used non-steady fluid flow theory to analyze the groundwater seepage affecting the landfill. The results show that the landfill could be divided into two units: the frontal unit (the landfill slope), with low water content, and the rear unit (fresh waste), with ponded water and high moisture levels. This structure created two effects to trigger the landslide at the landfill-surface water infiltration and consolidation seepage. We also used soil dynamic parameters of the landslide from cone penetration, triaxial, and ring-shear tests to simulate the characteristics of a flowing slide with a long run-out due to the liquefaction effect. The result suggested that the landslide had a maximum speed of about $30 \mathrm{~m} / \mathrm{s}$ with a maximum width of about $23 \mathrm{~m}$, and traveled about $610 \mathrm{~m}$ in $130 \mathrm{~s}$, at an apparent friction angle of $6^{\circ}$ (Fig. 10).

Figure 11 shows the simulation result from LS-RAPID of the landslide at the Shenzhen landfill, showing the movement and accumulation at different times. The red grids represent the moving landslide and the green grids represent the stable mountain and plain. Figure 11a at $0 \mathrm{~s}$ represents the initial state of the landslide, showing the morphological characteristics before the landslide failure. Figure $11 \mathrm{~b}$ at $5 \mathrm{~s}$ represents the launch of the landslide. The whole slope failure starts to move downward, with a speed of $14 \mathrm{~m} / \mathrm{s}$ and a movement distance of $480 \mathrm{~m}$. Figure $11 \mathrm{c}$ at $30 \mathrm{~s}$ represents the moving downward stage. The slide mass exits and the rear and its periphery collapse to the middle, with a maximum speed of $18 \mathrm{~m} / \mathrm{s}$ and a movement distance of $560 \mathrm{~m}$. Figure $1 \mathrm{~d}$ at $65 \mathrm{~s}$ represents the stage of continuous 

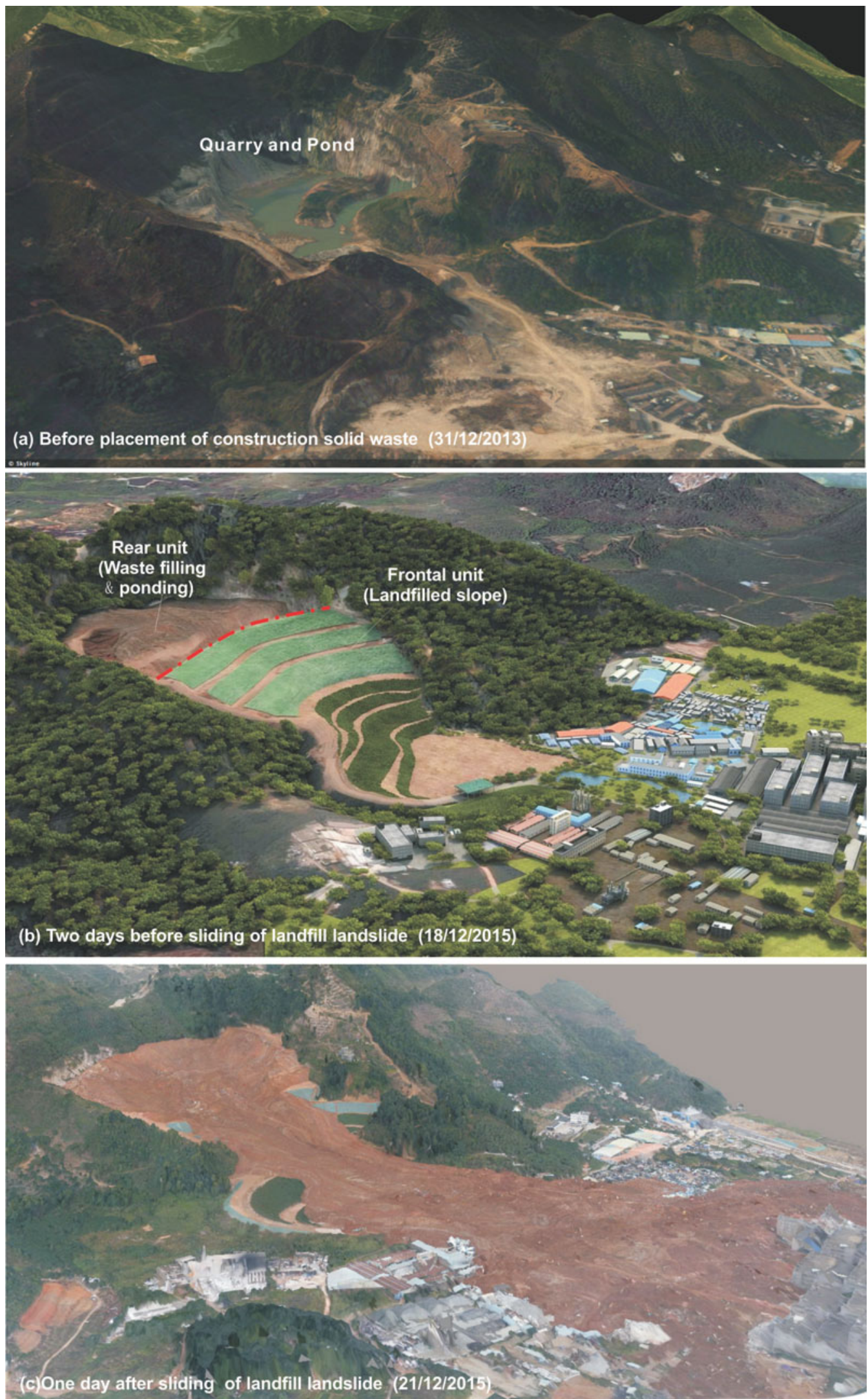

Fig. 9 Comparison of images showing the Hong'ao Village location, landfill, and landslide. a Remote-sensing image taken in December, 2013 (three months prior to CSW placement); b remote-sensing-based image taken on December 18, 2015 (two days before the landslide); and c aerial view taken on December 21, 2015 (one day after the landslide) from a UAV 


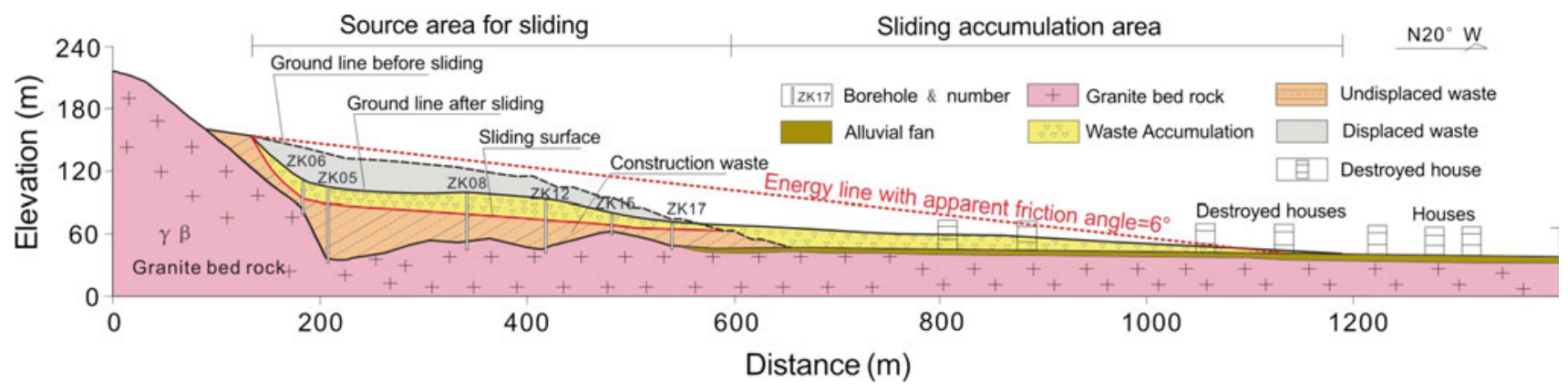

Fig. 10 Longitudinal profile of the landslide at the Shenzhen landfill. The energy line is indicated from scar of landslide to the front of accumulation with an angle of $6^{\circ}$ and the drilling holes after sliding reveal that the slip zone is translational with a angle of $4^{\circ}$. The landslide exits at the terrace $\mathrm{T} 1$
Fig. 11 Simulation result of the long run-out of the landslide at the Shenzhen landfill with LS-RAPID

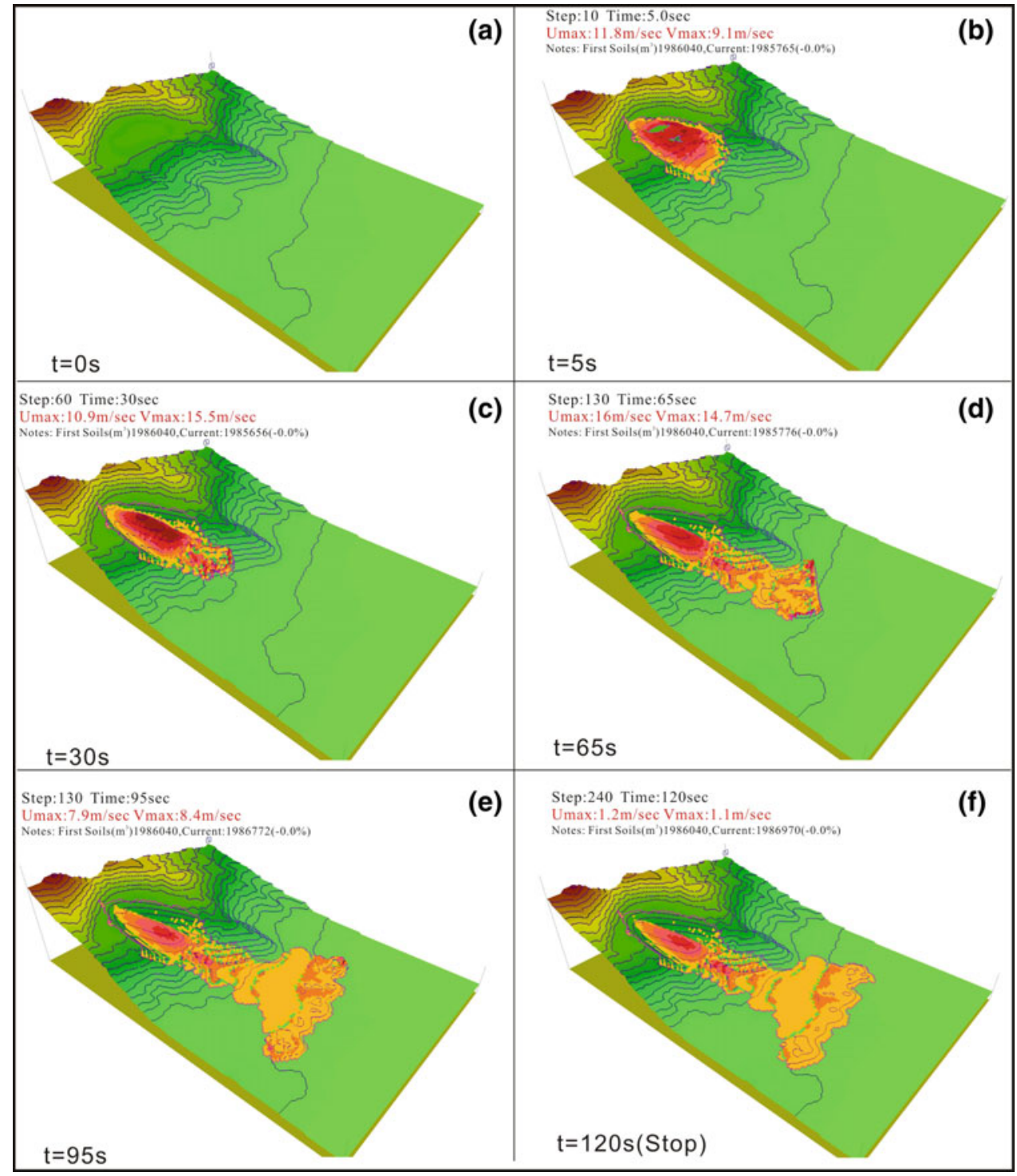


speed forward. The slide mass gradually disperses, with a maximum speed of $21.7 \mathrm{~m} / \mathrm{s}$ and a movement distance of $720 \mathrm{~m}$. Figure 21e at $95 \mathrm{~s}$ represents the decelerated motion stage. The accumulation is changing constantly, with a maximum speed of $11.5 \mathrm{~m} / \mathrm{s}$ and a movement distance of $920 \mathrm{~m}$. Figure $11 \mathrm{f}$ at $120 \mathrm{~s}$ represents the front accumulation stage. After dispersing over flat ground, the accumulation is still changing, with a maximum speed of $1.4 \mathrm{~m} / \mathrm{s}$ and a movement distance of $1060 \mathrm{~m}$.

Acknowledgements Our research activities in the field of landslide research have been mainly financed by the Ministry of Science and Technology, the Ministry of Land Resources and China Geological Survey. This financial support is greatly acknowledged.

\section{References}

Hungr O (1995) A model for the runout analysis of rapid flow slides, debris flows, and avalanches. Can Geotech J 32(4):610-623

Hungr O (2009) Numerical modeling of the motion of rapid, flow-like landslides for hazard assessment. KSCE J Civ Eng 13 (4):281-287
Sassa K, Nagai O, Solidum R, Yamazaki Y, Ohta H (2010) An integrated model simulating the initiation and motion of earthquake and rain induced rapid landslides and its application to the 2006 Leyte landslide. Landslides 7(3):219-236

Tang C, Zhu J, Ding J (2011) Catastrophic debris flows triggered by a 14 August 2010 rainfall at the epicenter of the Wenchuan Ms 8.0 Earthquake. Landslides 8:485-497

Yin YP, Wang FW, Sun P (2009) Landslide hazards triggered by the 2008 Wenchuan Ms 8.0 Earthquake, Sichuan, China. Landslides 6 (2):139-152

Yin YP, Cheng YL, Liang JT, Wang WP (2016a) Heavy-rainfallinduced catastrophic rockslide-debris flow at Sanxicun, Dujiangyan, after the Wenchuan Ms 8.0 earthquake. Landslides 13(1):9-23

Yin YP, Xing AG, Wang GH et al. (2016b) Experimental and numerical investigations of a catastrophic long-runout landslide in Zhenxiong, Yunnan, Southwestern China. Landslides. doi:10.1007/ s10346-016-0729-Z

Yin YP, Huang BL, Wang WP et al (2016c) Reservoir-Induced landslides and risk control in the Three Gorges Project, the Yangtze River, China. J Rock Mech Geotech Eng 8(5):577-589

Yin YP, Li B, Wang WP et al (2016d) Mechanism of the December 2015 catastrophic landslide at the Shenzhen landfill and controlling geotechnical risks of urbanization. Engineering 2 (2):230-249

Zhou W, Tang C (2013) Rainfall thresholds for debris flow initiation in the Wenchuan earthquake-stricken area, southwestern China. Landslides 11(5):877-887
Open Access This chapter is licensed under the terms of the Creative Commons Attribution 4.0 International License (http:// creativecommons.org/licenses/by/4.0/), which permits use, sharing, adaptation, distribution and reproduction in any medium or format, as long as you give appropriate credit to the original author(s) and the source, provide a link to the Creative Commons license and indicate if changes were made.
The images or other third party material in this chapter are included in the chapter's Creative Commons license, unless indicated otherwise in a credit line to the material. If material is not included in the chapter's Creative Commons license and your intended use is not permitted by statutory regulation or exceeds the permitted use, you will need to obtain permission directly from the copyright holder. 